\title{
ALMOST EVERYWHERE STRONG SUMMABILITY OF CUBIC PARTIAL SUMS OF D-DIMENSIONAL WALSH-FOURIER SERIES
}

\section{USHANGI GOGINAVA}

Abstract. In this paper we study the a. e. strong summability of the cubic partial sums of the d-dimensional Walsh-Fourier series of the functions belonging to $L\left(\log ^{+} L\right)^{d-1}$.

Mathematics subject classification (2010): 42C10.

Keywords and phrases: Walsh function, strong summability, cubic partial sums, Marcinkiewicz means.

\section{REFERENCES}

[1] N. Yu. ANTONOv, On the convergence almost everywhere of multiple trigonometric Fourier series over cubes (Russian), Izv. Ross. Akad. Nauk Ser. Mat. 68, 2 (2004), 3-22; translation in Izv. Math. 68, 2 (2004), 223-241.

[2] M. I. Dyachenko, On the $(C, \alpha)$-summability of multiple trigonometric Fourier series, Soobshch. Akad. Grusin 131, 2 (1988), 261-263 (Russian).

[3] L. FEJÉR, Untersuchungen über Fouriersche Reihen, Math. Annalen 58 (1904), 501-569.

[4] S. FRIDLI AND F. SCHIPP, Strong summability and Sidon type inequalities, Acta Sci. Math. (Szeged) 60, 1-2 (1995), 277-289.

[5] S. FRIDli AND F. SCHIPP, Strong approximation via Sidon type inequalities, J. Approx. Theory 94 (1998), 263-284.

[6] O. D. Gabisonia, On strong summability points for Fourier series, Mat. Zametki 14, 5 (1973), 615626.

[7] G. Gát, U. Goginava And G. Karagulyan, Almost everywhere strong summability of Marcinkiewicz means of double Walsh-Fourier series, Anal. Math. 40, 4 (2014), 243-266.

[8] G. GÁt, U. Goginava And G. Karagulyan, On everywhere divergence of the strong $\Phi$-means of Walsh-Fourier series, J. Math. Anal. Appl. 421, 1 (2015), 206-214.

[9] U. GoginaVA, Uniform convergence of Cesáro means of negative order of double Walsh-Fourier series, J. Approx. Theory 124, 1 (2003), 96-108.

[10] U. GoginaVA, The weak type inequality for the Walsh system, Studia Math. 185, 1 (2008), 35-48.

[11] U. Goginava And L. Gogoladze, Strong approximation by Marcinkiewicz means of twodimensional Walsh-Fourier series, Constr. Approx. 35, 1 (2012), 1-19.

[12] U. Goginava And L. GogoladZE, Convergence in measure of strong logarithmic means of double Fourier series, Izv. Nats. Akad. Nauk Armenii Mat. 49, 3 (2014), 39-49; translation in J. Contemp. Math. Anal. 49, 3 (2014), 109-116.

[13] U. Goginava, L. Gogoladze and G. Karagulyan, BMO-estimation and almost everywhere exponential summability of quadratic partial sums of double Fourier series, Constr. Approx. 40, 1 (2014), 105-120.

[14] B. I. Golubov, A. V. Efimov And V. A. Skvortsov, Series and transformations of Walsh, Moscow, 1987 (Russian); English translation, Kluwer Academic, Dordrecht, 1991.

[15] R. GETSADZE, On the boundedness in measure of sequences of superlinear operators in classes $L \phi(L)$, Acta Sci. Math. (Szeged) 71, 1-2 (2005), 195-226.

[16] L. GogoladZE, On the exponential uniform strong summability of multiple trigonometric Fourier series, Georgian Math. J. 16 (2009), 517-532.

[17] L. GogoladzE, Strong means of Marcinkiewicz type, (Russian), Soobshch. Akad. Nauk Gruzin. SSR 102, 2 (1981), 293-295. 
[18] V. A. Glukhov, Summation of multiple Fourier series in multiplicative systems, (Russian), Mat. Zametki 39, 5 (1986), 665-673.

[19] R. E. Edwards, Fourier series: a Modern Introduction, vol. 1, Springer-Verlang, New-Yourk, Heidelberg, Berlin 1982.

[20] G. H. Hardy and J. E. Littlewood, Sur la series de Fourier d'une fonction a carre sommable, Comptes Rendus (Paris) 156 (1913), 1307-1309.

[21] G. A. Karagulyan, Everywhere divergent $\Phi$-means of Fourier series, (Russian), Mat. Zametki 80, 1 (2006), 50-59; translation in Math. Notes 80, 1-2 (2006), 47-56.

[22] S. V. KonYAGIN, On the divergence of subsequences of partial sums of multiple trigonometric Fourier series, Trudy MIAN 190 (1989), 102-116.

[23] H. Lebesgue, Recherches sur la sommabilite forte des series de Fourier, Math. Annalen 61 (1905), 251-280.

[24] L. LEINDLER, Über die Approximation im starken Sinne, Acta Math. Acad. Hungar. 16 (1965), 255262.

[25] L. LeINDLER, On the strong approximation of Fourier series, Acta Sci. Math. (Szeged) 38 (1976), $317-324$.

[26] L. LeIndLER, Strong approximation and classes of functions, Mitteilungen Math. Seminar Giessen 132 (1978), 29-38.

[27] L. LeINDLER, Strong approximation by Fourier series, Akadémiai Kiadó, Budapest, 1985.

[28] J. Marcinkiewicz, Sur la sommabilité forte de séries de Fourier, (French), J. London Math. Soc. 14 (1939), 162-168.

[29] K. I. Os Kolkov, Strong summability of Fourier series, (Russian), Studies in the theory of functions of several real variables and the approximation of functions, Trudy Mat. Inst. Steklov 172 (1985), 280-290, 355.

[30] V. A. RoDin, The space BMO and strong means of Fourier series, Anal. Math. 16, 4 (1990), 291-302.

[31] V. A. Rodin, BMO-strong means of Fourier series, Funct. anal. Appl. 23 (1989), 73-74 (Russian).

[32] V. A. Rodin, The space BMO and strong means of Fourier-Walsh series (Russian), Mat. Sb. 182, 10 (1991), 1463-1478; translation in Math. USSR-Sb 74, 1 (1993), 203-218.

[33] F. SchIPP, On the strong summability of Walsh series, Publ. Math. Debrecen 52, 3-4 (1998), 611-633.

[34] F. SchIPP, Über die starke Summation von Walsh-Fourier Reihen, Acta Sci. Math (Szeged) 30 (1969), $77-87$.

[35] F. SchIPP, On strong approximation of Walsh-Fourier series, MTA III. Oszt. Kozl. 19, (1969), 101111 (Hungarian).

[36] F. SCHIPP AND N. X. Ky, On strong summability of polynomial expansions, Anal. Math. 12 (1986), $115-128$.

[37] F. Schipp, W. Wade, P. Simon And P. PÁL, Walsh Series, an Introduction to Dyadic Harmonic Analysis, Adam Hilger, Bristol, New York, 1990.

[38] P. SJöLIN, Convergence almost everywhere of certain singular integrals and multiple Fourier series, Ark. Mat. 9, (1971), 65-90.

[39] V. Tотік, On the strong approximation of Fourier series, Acta Math. Sci. Hungar. 35 (1980), 151172.

[40] V. Tотік, On the generalization of Fejér's summation theorem, Functions, Series, Operators, Coll. Math. Soc. J. Bolyai (Budapest) Hungary, 35, North Holland, Amsterdam-Oxford-New-York, 1980, $1195-1199$.

[41] V. Tотік, Notes on Fourier series: Strong approximation, J. Approx. Theory 43 (1985), 105-111.

[42] F. WeIsz, Convergence of double Walsh-Fourier series and Hardy spaces, Approx. Theory \& its. Appl. 17, 2 (2001), 32-44.

[43] F. WeIsZ, Summability of multi-dimensional Fourier series and Hardy space, Kluwer Academic, Dordrecht, 2002.

[44] F. WEIsZ, Strong summability of more-dimensional Ciesielski-Fourier series, East J. Approx. 10, 3 (2004), 333-354.

[45] F. WeIsZ, Strong Marcinkiewicz summability of multi-dimensional Fourier series, Ann. Univ. Sci. Budapest. Sect. Comput. 29 (2008), 297-317.

[46] F. WeISZ, Lebesgue points of double Fourier series and strong summability, J. Math. Anal. Appl. 432, 1 (2015), 441-462. 
[47] L. V. ZHIZHIASHVILI, Generalization of a theorem of Marcinkiwicz, Izvest.AN USSR, ser. matem. 32 (1968), 1112-1122 (Russian).

[48] A. Zygmund, Trigonometric series, Cambridge University Press, Cambridge, 1959. 